\title{
Running Condition Noise Dose to Auto drivers in Kolkata Metropolitan City of India in Different Seasons
}

\author{
Tirtharaj Sen, Pijush Kanti Bhattacharjee, Member,IACSIT, Debamalya Banerjee, Bijan Sarkar
}

\begin{abstract}
This paper studies work exposure for drivers of auto rickshaws in Kolkata, India in a running condition to noise. Since the most negative effects caused by noise exposure are related to the hearing system and it may produce professional deafness or even permanent deafness. It is necessary to assess the noise exposure and to develop mechanisms for studying and proposing preventive solutions for minimizing environmental pollution. Equivalent noise exposures of drivers at work and in-auto noise are evaluated using a precision dosimeter in different areas or locations of various times like summer and rainy seasons etc. Readings were taken in different routes in north Kolkata, India and the noise doses are analyzed. The A-weighted values of $L$ eq (12), L10, L90, TWA (Time weighted Average) and TNI (Traffic Noise Index) are determined. It shows significant effect of noise exposure from auto-rickshaws in Kolkata city of India.
\end{abstract}

Index Terms - precision dosimeter, vehicle flow, traffic composition, noise exposure

\section{INTRODUCTION}

Kolkata in India is the most populous metropolitan cities of the world with significant commuter flows according to Census of India, 200. There are about 75 thousand autorickshaws out of which 35 thousands are having license. Work exposure for the drivers involves heat, noise, diesel exhaust, the body vibration etc, causing noise and environmental pollution.

Maximum routes of this city are congested and roads are not properly designed. It has a large public transportation system involving significant environment pollution. Workexposures for the drivers, conductor and commuters in an

Tirtharaj Sen is an Assistant Professor in the Department of Electrical Engineering, Asansol Engineering College, Kanyapur, Vivekananda Sarani, Asansol,Burdwan-713305. He was an Ex Assistant Professor \& Head, Dept. of E.E, Bengal Institute of Technology and Management. He has twelve years Industrial experience and nearly six years teaching experience. (Phone: +91-9432851324, email: tirtha.bitm@gmail.com)

Pijush Kanti Bhattacharjee is an Assistant Professor in the Department of Electronics and Communication Engineering, Assam University, Assam, India. He was an Ex Asssitant Director in Department of Telecommunications (DoT), Government of India, India. He has possessed vast working experience in the field of Telecommunications including Mobile Communications, VLSI, Management etc during last 30 years. (phone: +91-33-25954148, email: pijushbhatta_6@hotmail.com).

Dr. Debamalya Banerjee, Ph.D(Engg.) is currently a Reader in the Department of Production Engg. which is a centre of Advanced study in Jadavpur University. $\mathrm{He}$ was a visiting scientist in LfE[Lehrstuhl fü Ergonomie], TUM[Technical University of Munich].

(Phone: +91-9432283650, email: debamalya_banerjee@yahoo.co.uk

Dr. Bijan Sarkar is currently a Professor in the Department of Production Engineering which is a centre of Advanced study in Jadavpur University, Kolkata, India. auto are mostly heat, noise, diesel exhaust, whole body vibration etc. The noise emitted from the engine, gear, clutch, accelerator, brake, etc. during operation of the auto are the main noise source within and outside the auto. Noise intensity varies with operating conditions and with the overall state of the autos. There are also other factorsstriking of metal body structures, horn, voice of the passengers etc. Moreover, while crossing different traffic zones, autos pass through the crowded areas and the outside noise contributes to the in-auto noise. The report of this study looks at exposures of the auto drivers in Kolkata metropolitan city of India.

\section{Methodology of THE StUdy}

For studying the characteristics of noise dose at different sites, simultaneous measurement of sound-pressure levels (SPL) at different routes in North Kolkata are taken in running condition in winter, summer season. Also Time Weighted sound-pressure level (TWA), threshold level, criterion levels were also made. A history of discomfort in running condition, regarding noise pollution, if any, experienced while driving the auto previously is obtained through questionnaire to different auto drivers in different routes of the city.

\section{A. Instrument Used}

Type 4444, Noise dose meter a lightweight and instrument has been used for recording assessment and of noise levels associated with auto drivers in Kolkata city. This meter type 4444 comes with different seven built in setups, which includes OSHA, MSHA, DOD, ACGIH (USA Standards) and ISO 85A, ISO 90A (International Standard) which corresponds to today's most widely used standard. There are two sound level meter setups: SLM which gives on-screen results only and cannot store data to memory. METER which can store data to memory.

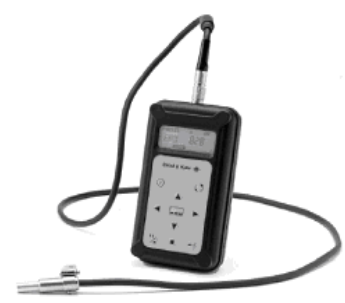

Fig.1. Noise Dose Meter 4444 used for this study

\section{B. Method of measurement}

Each route was studied at least 2 times during the to- 
and-fro journey. The noise, monitoring a weighted noise, Leq, is recorded for the driver by connecting the mouthpiece to the drivers collar (10cm approx. from the driver ear). It is estimated by recording the $\mathrm{dB}(\mathrm{A})$ value in Leq mode. The noise exposure of auto drivers is taken during January to end of July, 2010 over a period of 32 weeks, which cover winter, summer seasons. An area of north Kolkata is selected and measurement is taken in different routes in morning, noon and afternoon times.

The noise dose (ND) for drivers on each trip can be calculated from:

N.D $=\mathrm{T} / 8 \mathrm{X}$ antilog $\{0.1$ (L-90) $\}$, Where $\mathrm{T}$ is the duration in hours over a specified noise level reaches ear and $\mathrm{L}$ is level of noise reaching the ear in $\mathrm{dB}(\mathrm{A})$.

The Leq is calculated over a particular route from ND.

$$
\operatorname{Leq}=10 \log (\mathrm{ND})+90 \mathrm{~dB}(\mathrm{~A}) \cdot[1]
$$

$$
\text { Leq }=10 \log \left[\left(\frac{1}{T} \int_{0}^{T} P_{A}^{2}(\mathrm{t}) \mathrm{dt}\right) / \mathrm{P}^{2}{ }_{\text {ref }}\right] \mathrm{dB}(\mathrm{A})
$$

The recordings are taken when the auto rickshaws in motion. When the driver takes break for lunch, usually for half an hour i.e. $1 \mathrm{pm}$ to $1.30 \mathrm{pm}$, intervals are taken while an auto is idle in the stand.

TABLE 1. ROUTE CHART

\begin{tabular}{|c|c|c|}
\hline $\begin{array}{c}\text { Route } \\
\text { No }\end{array}$ & Name of Route & Location \\
\hline 1. & Sithirmore to Shyambazar & North Kolkata \\
\hline 2. & Shyambazar to Sithirmore & North Kolkata \\
\hline 3. & Sithirmore to Bally & North Kolkata \\
\hline 4. & Bally to Sithirmore & North Kolkata \\
\hline 5. & Shyambazar to Ahiritola & North Kolkata \\
\hline 6. & Ahiritola to Shyambazar & North Kolkata \\
\hline 7. & Ahiritola to Baghbazar & North Kolkata \\
\hline 8. & Baghbazar to Ahiritola & North Kolkata \\
\hline 9. & Ahiritola to Sovabazar & North Kolkata \\
\hline 10. & Sovabazar to Ahititola & North Kolkata \\
\hline 11. & Baghbazar to Sovabazar & North Kolkata \\
\hline 12. & Sovabazar to Baghbazar & North Kolkata \\
\hline
\end{tabular}

\section{Data Computation}

Data recorded from 10 A.M. to 6 P.M. (8 Hrs) at each route to compute the hourly equivalent continuous noise level Leq (8), traffic noise index (TNI), and the noise exceedance level L10, L90 are done.

The different formulas used for computation of these parameters are written down below:-

$$
\begin{aligned}
& \mathrm{TNI}=4\left(\mathrm{~L}_{10}-\mathrm{L}_{90}\right)+\mathrm{L}_{90}-30 \\
& \operatorname{Leq}(12)=10 \log \frac{1}{12} \sum_{i=1}^{12} 10^{\frac{L i}{10}}
\end{aligned}
$$

Results obtained from computation and from 4444 Noise Dose Meter are as follows:
TABLE 2. TRAfFic Noise INDEX \& EQUiVALENT Noise POLlution IN

\begin{tabular}{|c|c|c|c|c|}
\hline $\begin{array}{c}\text { No of } \\
\text { runs }\end{array}$ & $\mathbf{L}_{\mathbf{e q}}(\mathbf{d B A})$ & $\mathbf{L}_{\mathbf{1 0}} \mathbf{d B A}$ & $\mathbf{L}_{\mathbf{9 0}} \mathbf{d B A}$ & $\begin{array}{c}\text { TNI(Traffic } \\
\text { Noise Index) }\end{array}$ \\
\hline 1 & 82.2 & 91.2 & 73.84 & 113.28 \\
\hline 2 & 80.5 & 90.7 & 70.44 & 121.48 \\
\hline 3 & 87.0 & 99.2 & 72.94 & 147.98 \\
\hline 4 & 84.3 & 96.2 & 77.64 & 121.88 \\
\hline 5 & 81.3 & 97.5 & 71.14 & 146.58 \\
\hline 6 & 82.0 & 91.2 & 75.04 & 107.88 \\
\hline 7 & 89.1 & 93.0 & 75.64 & 115.08 \\
\hline 8 & 87.3 & 95.3 & 73.54 & 130.58 \\
\hline 9 & 84.1 & 98.02 & 72.74 & 113.86 \\
\hline 10 & 86.7 & 92.7 & 71.44 & 126.48 \\
\hline 11 & 86.7 & 91.1 & 74.14 & 111.98 \\
\hline 12 & 89.7 & 94.6 & 74.74 & 124.18 \\
\hline
\end{tabular}

Mean TNI is 123.43

Range for $\mathrm{TNI}=$ Maximum value - Minimum value $=$ $147.98-107.88=40.1$

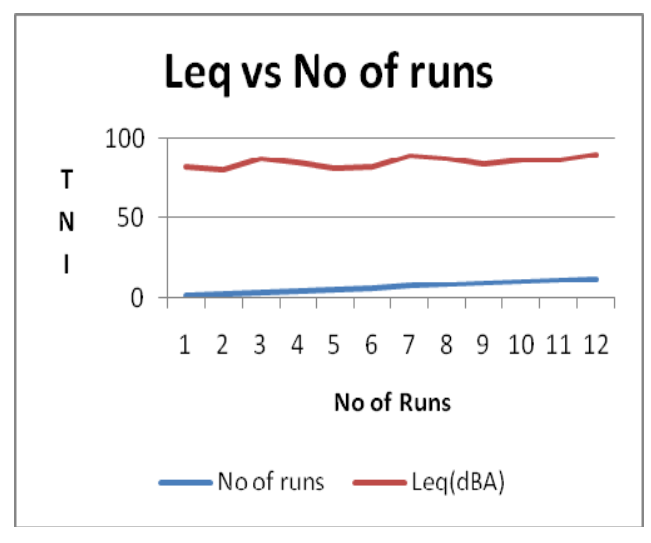

Fig. 2. Leq Vs No. of Runs (winter)

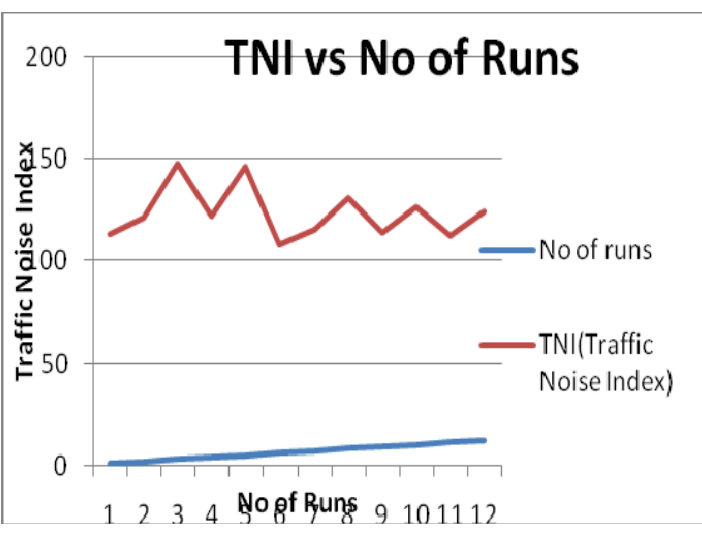

Fig. 3. TNI Vs No. of Runs (winter)

TABle 3. TRAFFic Noise IndeX \& EQUivalent Noise Pollution IN

\begin{tabular}{|c|c|c|c|c|}
\hline $\begin{array}{c}\text { No of } \\
\text { runs }\end{array}$ & $\mathbf{L}_{\text {eq }} \mathbf{d B A}$ & $\begin{array}{c}\mathbf{L}_{\mathbf{1 0}} \\
\mathbf{d B A}\end{array}$ & $\mathbf{L}_{\mathbf{9 0}} \mathbf{d B A}$ & $\begin{array}{c}\text { TNI (Traffic } \\
\text { Noise Index) }\end{array}$ \\
\hline 1 & 84.2 & 90.2 & 75.64 & 103.88 \\
\hline 2 & 87.3 & 99.1 & 73.54 & 145.78 \\
\hline 3 & 85.4 & 96.7 & 72.74 & 138.78 \\
\hline 4 & 83.3 & 99.3 & 71.44 & 152.88 \\
\hline 5 & 85.4 & 93.0 & 74.14 & 119.58 \\
\hline 6 & 83.1 & 95.3 & 74.74 & 126.98 \\
\hline
\end{tabular}




\begin{tabular}{|c|c|c|c|c|}
\hline 7 & 87.4 & 98.02 & 72.62 & 144.22 \\
\hline 8 & 88.01 & 91.2 & 75.11 & 109.47 \\
\hline 9 & 82.5 & 90.7 & 71.45 & 118.45 \\
\hline 10 & 87.4 & 99.2 & 75.34 & 140.98 \\
\hline 11 & 84.7 & 96.2 & 73.14 & 135.38 \\
\hline 12 & 82.2 & 97.5 & 72.04 & 143.88 \\
\hline
\end{tabular}

\begin{tabular}{|l|c|c|c|c|c|c|c|}
\hline 10. & 100 & 16.96 & 6.60 & 0.15 & 0.00 & 0.00 & 63.1 \\
\hline 11. & 97.79 & 18.81 & 2.62 & 0.08 & 0.00 & 0.00 & 61.7 \\
\hline 12. & 92.61 & 17.61 & 3.22 & 0.10 & 0.00 & 0.00 & 67.7 \\
\hline
\end{tabular}

Mean TNI is 131.67

Range for $\mathrm{TNI}=$ Maximum value-Minimum value $=152.88-103.88=49.00$

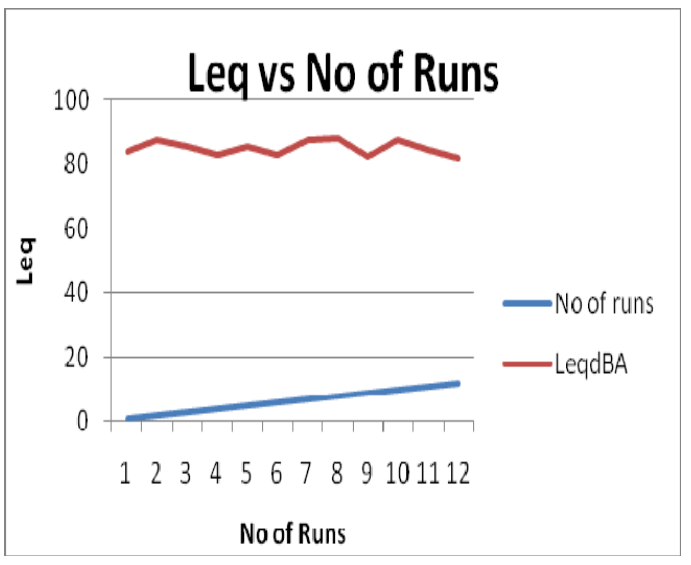

Fig. 4. Leq Vs No. of Runs (summer)

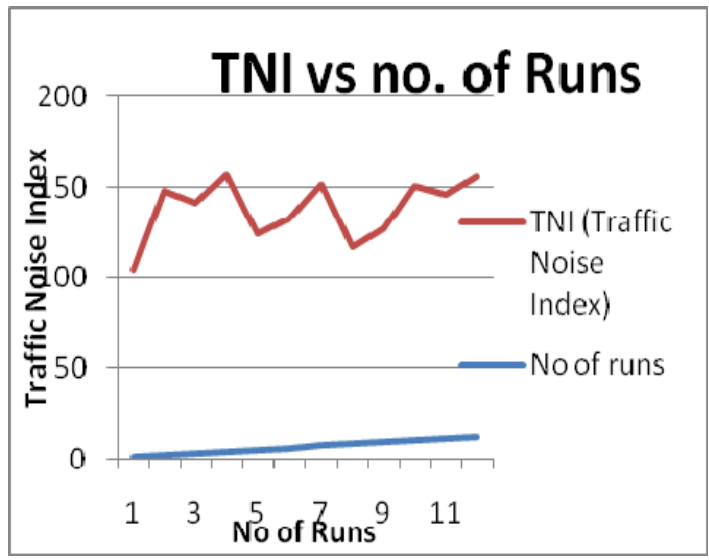

Fig. 5. TNI Vs No. of Runs (summer)

Time weighted Average (TWA) and Exceedance times (for $\%$ of runs from $70 \mathrm{~dB}-140 \mathrm{~dB}$ ) are taken by Noise Dose Meter as follows: -

TABle 4. Time Weighted Average (TWA) VERSus ExCEedANCE TIMES FOR PERCENTAGE OF RUNS FROM 70DB TO140DB

\begin{tabular}{|c|c|c|c|c|c|c|c|}
\hline $\begin{array}{c}\text { No. } \\
\text { of } \\
\text { Run } \\
\text { s }\end{array}$ & $70 \mathrm{~dB}$ & $85 \mathrm{~dB}$ & $90 \mathrm{~dB}$ & $\begin{array}{c}100 \mathrm{~d} \\
\mathrm{~B}\end{array}$ & $\begin{array}{c}115 \mathrm{~d} \\
\mathrm{~B}\end{array}$ & $\begin{array}{c}140 \mathrm{~d} \\
\mathrm{~B}\end{array}$ & $\begin{array}{c}\text { TWA } \\
(\mathrm{dB})\end{array}$ \\
\hline 1. & 95.18 & 17.99 & 4.62 & 0.21 & 0.00 & 0.00 & 39.7 \\
\hline 2. & 96.22 & 37.01 & 13.30 & 0.02 & 0.00 & 0.00 & 64.5 \\
\hline 3. & 91.01 & 58.31 & 5.99 & 0.52 & 0.00 & 0.00 & 66.6 \\
\hline 4. & 96.80 & 57.14 & 26.31 & 0.16 & 0.00 & 0.00 & 52.8 \\
\hline 5. & 100.1 & 56.65 & 3.74 & 0.04 & 0.00 & 0.00 & 42.6 \\
\hline 6. & 100.7 & 29.26 & 4.69 & 0.06 & 0.00 & 0.00 & 64.0 \\
\hline 7. & 99.74 & 35.50 & 5.79 & 0.03 & 0.00 & 0.00 & 51.6 \\
\hline 8. & 100 & 38.60 & 6.60 & 0.27 & 0.00 & 0.00 & 48.2 \\
\hline 9. & 91.19 & 52.37 & 18.38 & 0.10 & 0.00 & 0.00 & 61.0 \\
\hline
\end{tabular}

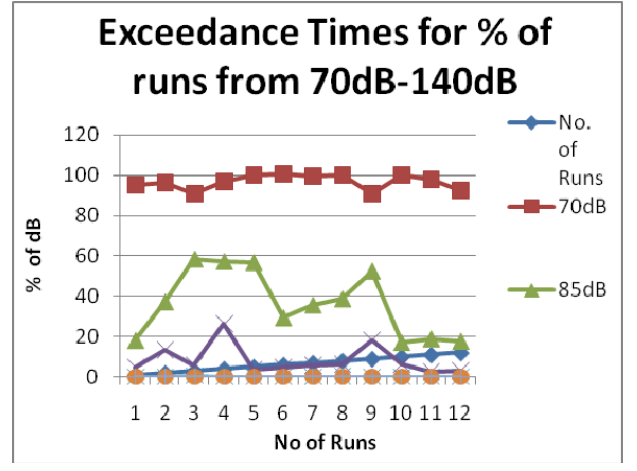

Fig. 6. Percentage runs from $70 \mathrm{~dB}-140 \mathrm{~dB}$

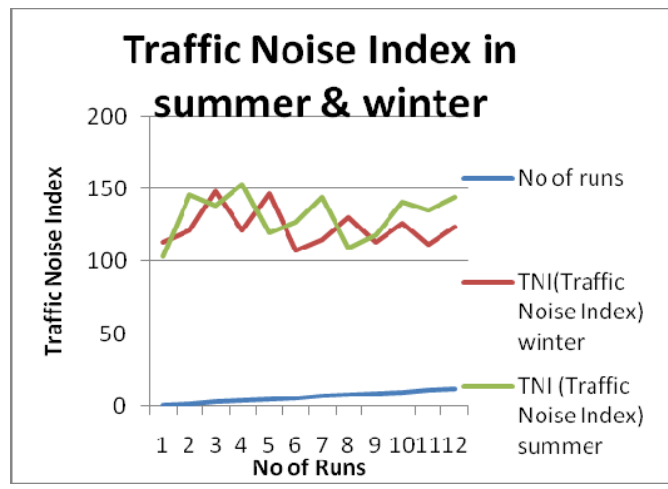

Fig. 7. TNI in summer \& winter

TABLE 5. INTERMEDIATE NOISE DOSE IN PERCENTAGE

\begin{tabular}{|l|c|c|c|c|c|}
\hline $\begin{array}{l}\text { No. } \\
\text { of } \\
\text { Run } \\
\text { s }\end{array}$ & $\begin{array}{l}70 \mathrm{~dB}- \\
85 \mathrm{~dB}\end{array}$ & $\begin{array}{l}85 \mathrm{~dB}- \\
90 \mathrm{~dB}\end{array}$ & $\begin{array}{l}90 \mathrm{~dB}- \\
100 \mathrm{~dB}\end{array}$ & $\begin{array}{l}100 \mathrm{~dB}- \\
115 \mathrm{~dB}\end{array}$ & $\begin{array}{l}115 \mathrm{~dB}- \\
140 \mathrm{~dB}\end{array}$ \\
\hline 1. & 17.19 & 13.37 & 4.41 & 0.21 & 0.00 \\
\hline 2. & 59.21 & 23.71 & 13.28 & 0.02 & 0.00 \\
\hline 3. & 32.7 & 52.32 & 5.47 & 0.52 & 0.00 \\
\hline 4. & 39.66 & 30.83 & 26.15 & 0.16 & 0.00 \\
\hline 5. & 43.46 & 52.91 & 3.7 & 0.04 & 0.00 \\
\hline 6. & 71.44 & 24.57 & 4.63 & 0.06 & 0.00 \\
\hline 7. & 64.24 & 29.71 & 5.76 & 0.03 & 0.00 \\
\hline 8. & 61.4 & 32.00 & 6.33 & 0.27 & 0.00 \\
\hline 9. & 38.82 & 33.99 & 18.28 & 0.10 & 0.00 \\
\hline 10. & 83.04 & 10.36 & 6.45 & 0.15 & 0.00 \\
\hline 11. & 78.98 & 16.19 & 2.54 & 0.08 & 0.00 \\
\hline 12. & 75 & 14.39 & 3.12 & 0.10 & 0.00 \\
\hline
\end{tabular}

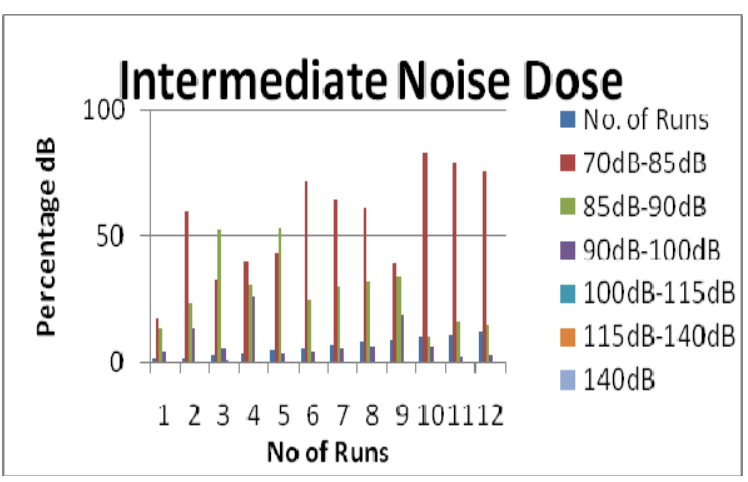

Fig. 8. Intermediate Noise Dose from $70 \mathrm{~dB}$ to $140 \mathrm{~dB}$ 


\section{RESUlts AND DiscussiOn}

Table 2 and Table 3 represents the equivalent continuous noise exposure in $\mathrm{dB}(\mathrm{A})$ as well as Traffic Noise Index (TNI) in twelve different runs in running condition in summer and winter seasons. Criterion level and threshold level are always kept in $90 \mathrm{~dB}$ and $80 \mathrm{~dB}$ respectively. The different values of the noise variables recorded on different runs in the dose meter are shown above in the above tables, line and bar diagram.

\section{CONCLUSIONS}

From above it has been found that Traffic Noise Index is Maximum in summer and it is 152.88 and Mean Time Weighted Average (TWA) is 56.95. It was observed that the proportions of drivers by category of sensitivity of hearing are an important factor in running condition and the proportion of drivers with a hearing loss increases significantly. In summer Mean TNI is 131.67 and in winter 123.43. So the difference of Mean TNI in these two seasons is 08.24. Drivers undertaking four consecutive trips within Kolkata city traffic routes have higher noise exposure than the recommended standard. This study suggests that noise exposure and noise induced hearing loss and occupational noise exposure both interfere with the safety of driver as well as passenger's daily life. It is found that working in such places where daily noise dose exceed $89 \mathrm{dBA}$ is more dangerous, even for those suffering from mild noise related hearing loss. If noise exposure can be reduced, then it will decrease the tendency of drivers to cause accident and injury because inability to hear auditory warning signals, or too uncertain about their presence. Thus appropriate action cannot be taken in time from the part of the auto drivers. Apart from this, long exposure to this level of noise, it is sure to produce short term and long term hearing disorders causing serious type of environmental pollution. Though this study is carried out only with auto-rickshaws i.e. small vehicle in Kolkata metropolitan city of India, similar study can be easily extended to other mode of vehicles i.e. light and heavy vehicles in all around the world. The results indicate how much the auto-drivers, passengers and road commuters of Kolkata in India are exposed to high intensity of noise pollution.

\section{REFERENCES}

[1] A.K. Mukherjee S.K. Bhattacharya S. Ahmed S.K. Roy A. Roychowdhury S. Sen "Exposure of drivers and conductors to noise, heat, dust and volatile organic compounds in the state transport special buses of Kolkata city".

[2] Bru“ el, Kjær, 1998a. Technical Documentation-Sound Calibrator BK4231. Bru“" el and Kjær, Naerum, Denmark.

[3] Bru“ el, Kjær, 1998b. Technical Documentation-Integrating and Logging Sound level meterBK 2238 and BK 2260. Bru“ el and Kjær, Naerum, Denmark.

[4] Griefahn B., Marks A., Robens S. "Noise emitted road road, rail, and air traffic and their effects on sleep". J. of Sound and Vibr. 295(2006) 129-140.

[5] Goelzer, B., Hansen, C.H., Sehrndt, G., 2001. Occupational Exposure to Noise: Evaluation, Prevention and Control. Publication Series from the Federal Institute for Occupational Safety and Health, Document published on behalf of the World Health Organization, (Dortmund, Berlin).

[6] Picard Michel, Girard S.A, Simard M, Larocque R. Leroux T., Turcotte F." Accident Analysis and Prevention" J. Elevier 40(2008), 1644-1652.
[7] Tirtharaj Sen, Dr. Debamalya Banerjee, Prof. Bijon Sarkar "Exposure of Auto drivers to NoiseDose, in Running Condition in the Kolkata City of West Bengal State"- HWWE 2009, Calcutta University, Kolkata.

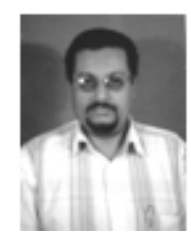

Mr. Tirtharaj Sen is an Assistant Professor in the Department of Electrical Engineering, Asansol Engineering College, Kanyapur, Vivekananda Sarani, Asansol, Burdwan-713305, India. He obtained his B.E (Electrical), M-Tech(Electrical Power) both from Calcutta University and pursuing $\mathrm{PhD}$ at Jadavpur University. He has twelve years Industrial experience in Hindustan Motors Limited(1989-2001). He was an Ex Assistant Professor \& Head, Dept. of E.E, Bengal Institute of Technology and Management, Santiniketan. (2005-2010). He has a number of publications [Both in Journals \& in Proceedings of Conferences, National \& International]. He is a member of Institution of Engineers (India)(MIE) and IEEE. His research interests are in Noise Pollution, Harmonics and Non Conventional Energy.

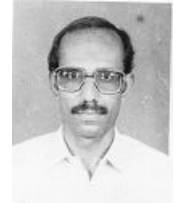

Mr. Pijush Kanti Bhattacharjee is associated with the study in Engineering, Management, Law, Indo-Allopathy, Herbal, Homeopathic \& Yogic medicines. He is having qualifications M.E, MBA, MDCTech, A.M.I.E (B.E or B.Tech), B.Sc(D), BIASM, CMS, PET, EDT, FWT, DATHRY, B.A, LLB, KOVID, DH, ACE, FDCI etc. He has started service in Government of India, Department of Telecommunications (DoT) since 1981 as an Engineer, where he has worked upto January, 2007, lastly holding Assistant Director post at Telecom Engineering Centre, DoT, Kolkata, India. Thereafter, he worked at IMPS College of Engineering and Technology, Malda, WB, India as an Assistant Professor in the Department of Electronics and Communication Engineering from January 2007 to Feb 2008, from Feb 2008 to Dec 2008 at Haldia Institute of Technology, Haldia, WB, India, from Dec 2008 to June 2010 at Bengal Institute of Technology and Management, Santiniketan, WB, India, June 2010 to Aug 2010 at Camellia Institute of Technology, Kolkata, India. He joined at Assam University, Assam, India in Sept 2010 in the same post and department. He has written two books "Telecommunication India" \& "Computer". He is a member of IACSIT, Singapore; CSTA, USA; IAENG, Hongkong; and IE, ISTE, IAPQR, IIM, India. His research interests are in Mobile Communications, Image Processing, VLSI, Nanotechnology, Management and Environmental Pollution etc.

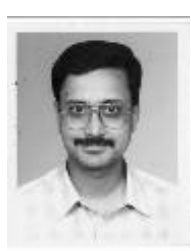

Dr. Debamalya Banerjee, Ph.D(Engg.) is currently a Reader in the Department of Production Engg. which is a centre of Advanced study in Jadavpur University, which has been rated a "Five Star University"[Highest accreditation],by NAAC[National Assessment and Accreditation Council] the official Accreditation Agency of U.G.C of Govt. of India. He has in his credit a number of publications[Both in Journals \& in Proceedings of Conferences, National \& International]. He was a visiting scientist in LfE[Lehrstuhl fur Ergonomie],TUM[Technical University of Munich], Germany and currently looks after all the Ergonomics related activities of the Department, as well as, the University. He has successfully conducted projects on Ergonomics and is currently a Life Member of Indian Society of Ergonomics (ISE), which is federated to the IEA [International Ergonomics Association].

Dr. Bijan Sarkar did his Bachelor and Master of Production Engg. From Jadavpur University, Calcutta, India. Dr. Sarkar has done Doctor of Philosophy (PhD) also from Jadavpur University. He has 15 years of Experioence in the field of teaching, consultancy and research. Dr. Sarkar has published more than 113 papers in National and International conferences and Journals and got the award of Bharat Gaurav. Presently Dr. Sarkar is Professor of Production Engineering Depatment, Jadavpur University, Kolkata. His field of interest includes of Al Techniques in Mechanical, Production Management, Tribology. He is a Life Member of Institution of Engineers (India), Indian Society of Technical Education, Society of Reliability Engineers etc. 